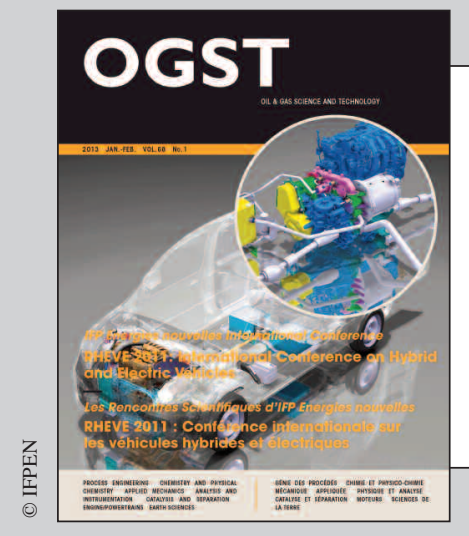

Dossier

This paper is a part of the hereunder thematic dossier published in OGST Journal, Vol. 68, No. 1, pp. 3-178 and available online here

Cet article fait partie du dossier thématique ci-dessous publié dans la revue OGST, Vol. 68, n 1 , pp. 3-178 et téléchargeable ici

DOSSIER Edited by/Sous la direction de : A. Sciarretta, F. Badin et J. Bernard RHEVE 2011 : International Conference on Hybrid and Electric Vehicles RHEVE 2011 : Conférence internationale sur les véhicules hybrides et électriques

Oil \& Gas Science and Technology - Rev. IFP Energies nouvelles, Vol. 68 (2013), No. 1, pp. 3-178

Copyright (C) 2013, IFP Energies nouvelles

\section{$3>$ Editorial}

$13>$ Analysis and Experimental Implementation of a Heuristic Strategy for Onboard Energy Management of a Hybrid Solar Vehicle

Analyse et expérimentation d'une stratégie heuristique pour la gestion d'énergie à bord d'un véhicule hybride solaire

G. Coraggio, C. Pisanti, G. Rizzo and M. Sorrentino

23 > Open Issues in Supervisory Control of Hybrid Electric Vehicles: A Unified Approach Using Optimal Control Methods

Questions ouvertes sur la supervision énergétique des véhicules hybrides électriques : une approche unifiée par la théorie de la commande optimale

L. Serrao, A. Sciarretta, 0. Grondin, A. Chasse, Y. Creff, D. Di Domenico, P. Pognant-Gros, C. Querel and L. Thibault

35 > Optimization of Hybrid Power Trains by Mechanistic System Simulations

Optimisation de groupes motopropulseurs électriques hybrides par simulation du système mécanique

T. Katrašnik and J.C. Wurzenberger

51 > A Phenomenological Heat Transfer Model of SI Engines - Application to the Simulation of a Full-Hybrid Vehicle

Un modèle phénoménologique de transfert thermique au sein de moteurs à allumage commandé - Application à la simulation d'un véhicule full-hybride

R. Dubouil, J.-F. Hetet and A. Maiboom

$65>$ Battery Electric Vehicle (BEV) or Range Extended Electric Vehicle (REEV)? - Deciding Between Different Alternative Drives Based on Measured Individual Operational Profiles

Véhicule électrique à batteries (BEV) ou véhicule électrique à prolongateur d'autonomie (REEV) ? - Choisir entre différents entrânements alternatifs sur la base de profils opérationnels individuels mesurés

S. Marker, B. Rippel, P. Waldowski, A. Schulz and V. Schindler

$79>$ Assessment by Simulation of Benefi ts of New HEV Powertrain Configurations

Évaluation par simulation des bénéfi ces de nouvelles chaînes de traction hybrides

N. Kim and A. Rousseau
95 > Dual Mode Vehicle with In-Wheel Motor: Regenerative Braking Optimization

Véhicule bi-mode avec moteurs roues : optimisation du freinage récupératif

G. Le Solliec, A. Chasse, J. Van-Frank and D. Walser

109 > Engine Downsizing and Electric Hybridization Under Consideration of Cost and Drivability

Réduction de taille moteur et hybridation électrique avec considérations de coût et de performance de conduite

S. Ebbesen, P. Elbert and L. Guzzella

117 > Representative Midwestern US Cycles: Synthesis and Applications Cycles représentatifs du Middle West américain : synthèse et applications

T.-K. Lee and Z.S. Filipi

127 > A Review of Approaches for the Design of Li-lon BMS Estimation Functions

Revue de différentes approches pour l'estimation de l'état de charge de batteries Li-ion

D. Di Domenico, Y. Creff, E. Prada, P. Duchêne, J. Bernard and V. Sauvant-Moynot

137 > Experimental Assessment of Battery Cycle Life Within the SIMSTOCK Research Program

Évaluation expérimentale de la durée de vie de la batterie dans le programme de recherche SIMSTOCK

P. Gyan, P. Aubret, J. Hafsaoui, F. Sellier, S. Bourlot, S. Zinola and F. Badin

$149>$ Smart Battery Thermal Management for PHEV Efficiency Une gestion avancée de la thermique de la batterie basse tension de traction pour optimiser l'efficacité d'un véhicule hybride électrique rechargeable

L. Lefebvre

$165>$ Parameterization and Observability Analysis of Scalable Battery Clusters for Onboard Thermal Management

Paramétrage et analyse d'observabilité de clusters de batteries de taille variable pour une gestion thermique embarquée

Xinfan Lin, Huan Fu, Hector E. Perez, Jason B. Siege, Anna G. Stefanopoulou, Yi Ding and Matthew P. Castanier 


\title{
Assessment by Simulation of Benefits of New HEV Powertrain Configurations
}

\author{
N. Kim and A. Rousseau* \\ Argonne National Laboratory, 9700 S. Cass Avenue, Argonne, IL, 60439-4815 - USA \\ e-mail: nkim@anl.gov - arousseau@anl.gov \\ * Corresponding author
}

Résumé - Évaluation par simulation des bénéfices de nouvelles chaînes de traction hybrides Durant les dernières années, de nombreuses configurations de motorisation pour véhicules hybrides ont été introduites sur le marché. La solution dominante est actuellement la dérivation de puissance en configuration 'input split' simple mode utilisée par Toyota et Ford. General Motors (GM) a récemment introduit une configuration basée sur la dérivation de puissance avec deux modes pour application sur des SUV (Sport Utility Vehicle). Par ailleurs, le premier véhicule hybride rechargeable - la Volt de GM - a été introduite sur le marché en 2010. La Volt utilise une architecture qui autorise plusieurs modes : électrique, série et dérivation de puissance, et qui est plus performante que l'architecture série mise en œuvre généralement pour les véhicules électriques à prolongateur d'autonomie (E-REV, Electric-Range Extended Vehicles). Ce papier est dédié à l'étude des bénéfices de différentes motorisations : simple mode contre multi-mode pour les véhicules hybrides, série contre GM Voltec pour les véhicules hybrides rechargeables. Le dimensionnement des composants, leur rendement ainsi que celui du système et la consommation énergétique sur différents cycles sont étudiés. Un modèle dynamique détaillé avec son algorithme de contrôle a été développé pour chacune des configurations considérées. Les composants des motorisations ont été dimensionnés pour satisfaire aux exigences d'autonomie tout électrique ainsi qu'aux performances dynamiques et de franchissement. Cette étude présente et compare l'impact de différentes chaînes de traction sur le dimensionnement des composants et leur consommation énergétique.

\begin{abstract}
Assessment by Simulation of Benefits of New HEV Powertrain Configurations During the past couple of years, numerous powertrain configurations for Hybrid Electric Vehicles (HEV) have been introduced into the marketplace. The current dominant architecture is the power-split configuration with the input split (single-mode) from Toyota and Ford. General Motors (GM) recently introduced a two-mode power-split configuration for applications in sport utility vehicles. Also, the first commercially available Plug-In Hybrid Electric Vehicle (PHEV) — the GM Volt — was introduced into the market in 2010. The GM Volt uses a series-split powertrain architecture, which provides benefits over the series architecture, which typically has been considered for Electric-Range Extended Vehicles (E-REV). This paper assesses the benefits of these different powertrain architectures (single-mode versus multi-mode for $H E V$ ) (series versus $G M$ Voltec for PHEV) by comparing component sizes, system efficiency and fuel consumption over several drive cycles. On the basis of dynamic models, a detailed component control algorithm was developed for each configuration. The powertrain components were sized to meet all-electric-range, performance and grade-capacity requirements. This paper presents and compares the impact of these different powertrain configurations on component size and fuel consumption.
\end{abstract}




\section{ABBREVIATIONS}

$\begin{array}{ll}\text { AHS } & \text { Advanced Hybrid System } \\ \text { BK } & \text { Brake } \\ \text { CL } & \text { Clutch } \\ \text { EV } & \text { Electric Vehicle } \\ \text { EVT } & \text { Electro-mechanical infinitely Variable } \\ & \text { Transmission } \\ \text { FG } & \text { Fixed Gear } \\ \text { FWD } & \text { Front-Wheel Drive } \\ \text { HEV } & \text { Hybrid Electric Vehicle } \\ \text { HWFET } & \text { HighWay Fuel Economy Test } \\ \text { ICE } & \text { Internal Combustion Engine } \\ \text { MC } & \text { Electric Machine/Motor } \\ \text { MP } & \text { Mechanical Point } \\ \text { NEDC } & \text { New European Drive Cycle } \\ \text { PG } & \text { Planetary Gear } \\ \text { PHEV } & \text { Plug-in Hybrid Electric Vehicle } \\ \text { PT } & \text { Powertrain } \\ \text { RG } & \text { Reduction Gear } \\ \text { RWD } & \text { Rear-Wheel Drive } \\ \text { SOC } & \text { State-of-Charge } \\ \text { SR } & \text { Speed Ratio } \\ \text { SUV } & \text { Sport Utility Vehicle } \\ \text { TM } & \text { Transmission } \\ \text { UDDS } & \text { Urban Dynamometer Driving Schedule }\end{array}$

\section{INTRODUCTION}

Various Hybrid Electric Vehicle (HEV) architectures have been proposed - one of the earliest and most commercially successful systems has been the power split, as used on all three generations of the Toyota Prius (as well as other Toyota/Lexus models) and on the Ford Escape. The powertrain configuration of the power-split hybrid system, sometimes referred as the parallel/series hybrid, combines the previous two configurations with a power-split device. It is appealing because with a proper control strategy, it can be designed to take advantage of both parallel and series types while avoiding their disadvantages. A major advantage of this configuration is the potential to de-couple the ICE and wheel speed as long as the output power demand is met, which offers greater flexibility in terms of choosing the ICE working point to optimize fuel consumption [1,2].

However, in the power-spilt configuration, the internal power circulation occurs along the closed loop (depending on the speed ratio), and sometimes the circulated power increases enormously. This power circulation can lead to high losses and, as a result, low efficiency of the power transmission. Such drawbacks can be addressed by combining several EVT (Electromechanical infinitely Variable Transmission) modes into one multi-mode hybrid system, thereby increasing the number of mechanical points and allowing greater operation flexibility. Various multi-mode EVT design configurations have been proposed, as indicated by patents and publications [3-7].

In an HEV, because the battery is charged only by the engine and not by plugging it into an external power source, electric driving range is limited because of the battery's relatively small capacity. Compared to the common HEV, a Plug-in Hybrid Electric Vehicle (PHEV) has greater potential for improved fuel efficiency and reduced emissions because it allows full electric driving and can easily use electric power provided by the home electricity grid [8]. A PHEV is also capable of long-distance travel because of its HEV function. PHEVs are gaining more attention in the automobile industry because of their advantages, but there have been few comparative studies on their powertrains because they require a different control algorithm than HEV, depending on the configuration of the PHEV.

When a vehicle is designed for a specific application, the goal is to select the powertrain configuration that maximizes the fuel displaced and yet minimizes the sizes of components. In the first part of this study, we evaluate the benefits of several multi-mode powertrain configurations with regard to size and fuel consumption for HEV. Each powertrain is sized to represent a small-size Sport Utility Vehicle (SUV) application, following the same vehicle technical specifications, such as acceleration and gradeability. In the second part, a comparative study is conducted on a GM Volt and a series plug-in hybrid for a PHEV. Two vehicle-powertrain configurations are sized to achieve similar performance for AllElectric Range (AER) approaches, on the basis of a mid-sized vehicle application. The component sizes and the fuel economy of each option are examined.

\section{DESCRIPTION OF POWERTRAIN SYSTEM}

\subsection{HEV Powertrain System}

\subsubsection{Single-Mode EVT}

Figure 1 is a schematic diagram of the single-mode power split Transmission (TM) with a Reduction Gear (RG). Because the input power from the ICE is split at the planetary gear, which is located at the input side, and the power transmission characteristic is represented by a single relationship for the whole speed range, this 


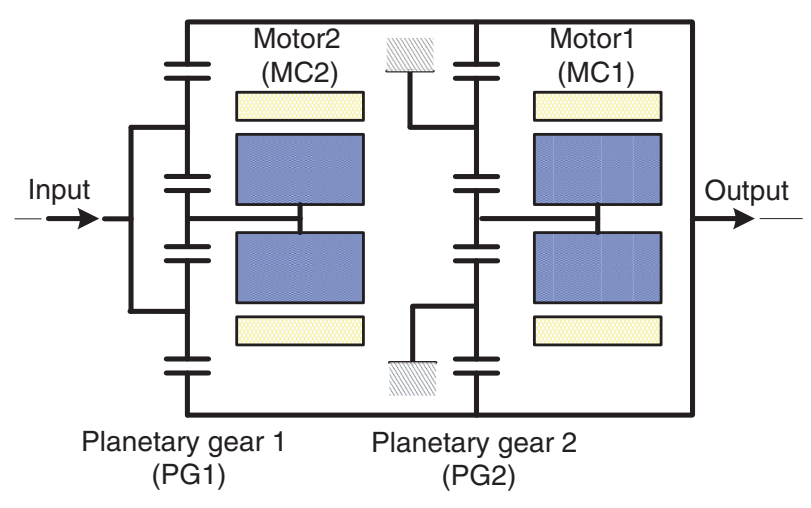

Figure 1

Schematic of the single-mode EVT.

power-split configuration is called the "input-split type" or "single-mode EVT". This input-split configuration consists of two planetary gears and two electric machines (MC1 and MC2). The larger electric machine on the right $(\mathrm{MC1})$ is connected to the output shaft through the second planetary gear and does not affect the speed ratio. Therefore, for this particular EVT arrangement (which maximizes the output torque), the speed of the output is the weighted average of the speed of the input and the speed of MC2. The second planetary gear set multiplies the torque from the input and both of the electric motors during input-split operation. For comparison, the single-mode powertrain without $R G$ is also investigated in this study.

In Figure 2, the electro-mechanical power ratio and the EVT system efficiency $(\eta)$ are plotted with respect to the Speed Ratio (SR). In this analysis, it is assumed that there is no power loss through the all-mechanical path and only electric machine loss is considered by using the efficiency maps of electric machines. The power ratio is defined as the ratio of the electro-mechanical power to the ICE input power, and the SR is defined as the ratio of the ICE input speed to output speed. In high SR range, the system efficiency is low because the electrical machines have relatively low efficiency. This low system efficiency can be avoided by propelling the vehicle by using the electric motor directly instead of using the engine. When $\mathrm{SR}=0.7$, the electro-mechanical power ratio becomes 0 , and all the power is transmitted through the mechanical part. This point is called the Mechanical Point (MP). The system efficiency shows the highest value at the MP. For SR $<0.7$, the electromechanical power ratio has a negative $(-)$ value, which means that the power is circulating along the closed path. Clearly, the circulated power increases as the SR
Ratio P-elect to P-eng (at W-eng $=1500 \mathrm{rpm}, \mathrm{T}$-eng $=100 \mathrm{Nm}$ )
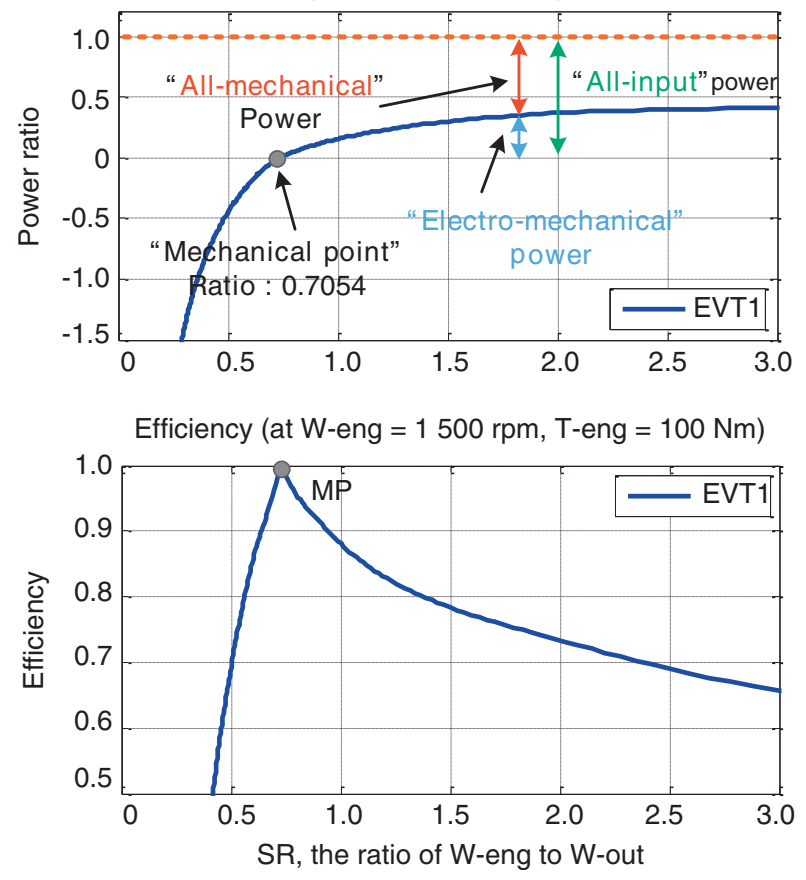

Figure 2

Power characteristics of the single-mode EVT.

decreases. Once the power circulation occurs, EVT efficiency decreases as a result of the relatively low efficiency of the electro-mechanical power path. The high circulated power results in decreased transmission efficiency and requires large electric machines. In addition, the high power requires consideration of the mechanical part design. The analysis results demonstrate why the Toyota Hybrid System (THS), a typical example of the input-split HEV, adopts large-capacity electric machines.

\subsubsection{Two-Mode EVT with Fixed-Gear Ratios}

Figure 3 is a schematic of the two-mode hybrid, which is called the General Motors Advanced Hybrid System2 (AHS2) for Front-Wheel Drive (FWD) [5]. This system has an additional stationary clutch and an additional rotating clutch. Through engaging or disengaging the four clutches, this system realizes six different operation modes, including two EVT modes and four Fixed-Gear (FG) modes. When operated in any of the four fixedgear modes, the vehicle is comparable to a parallel pretransmission HEV.

In Figure 4, the two-mode EVT already has a native fixed gear ratio, the synchronous shift ratio, in which 


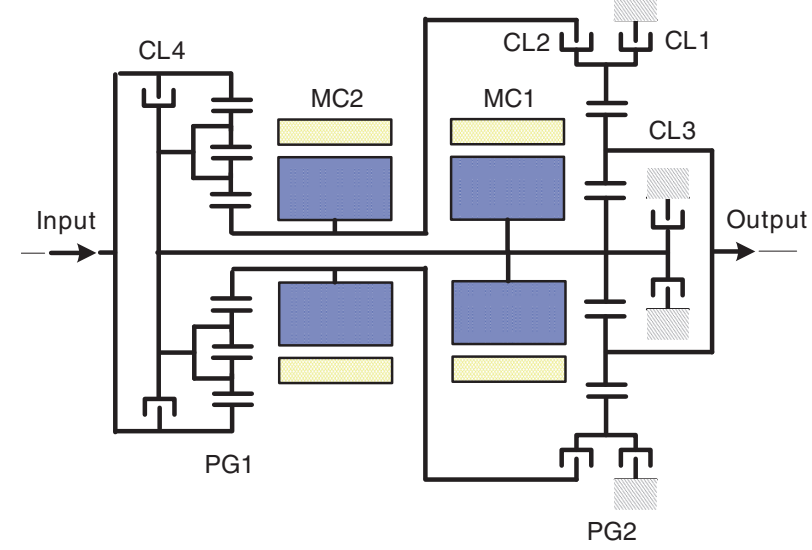

Figure 3

Schematic of the two-mode EVT with FG.

Ratio P-elect to P-eng

$($ at $\mathrm{W}$-eng $=1500 \mathrm{rpm}, \mathrm{T}$-eng $=100 \mathrm{Nm}$ )
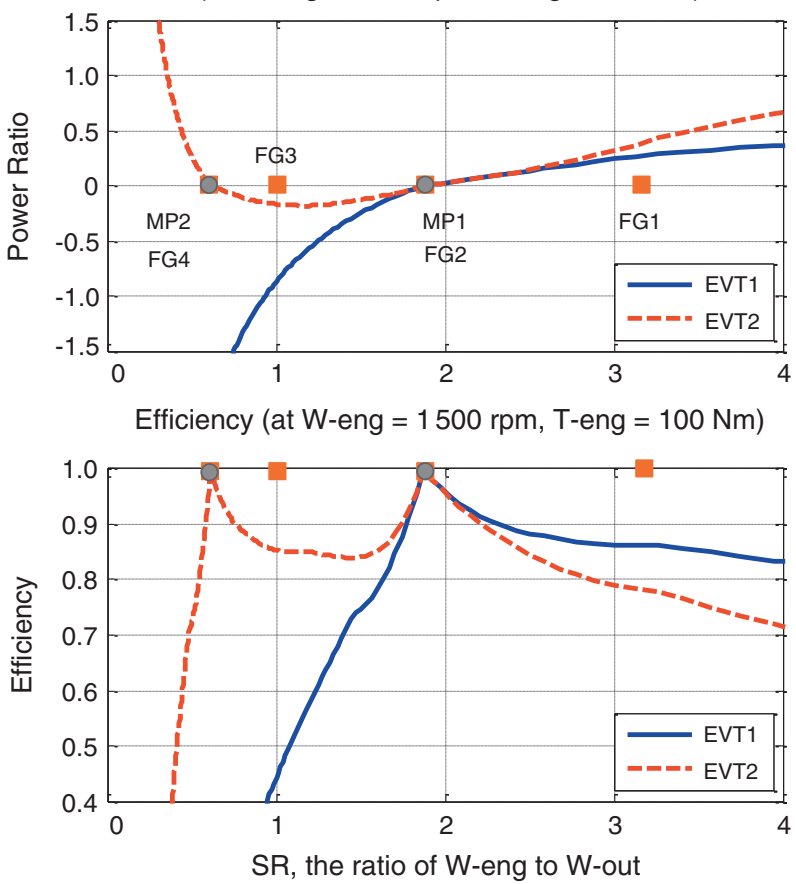

Figure 4

Power characteristics of the two-mode EVT with FG.

the action of two clutches at the same time provides a fixed ratio. For the two-mode hybrid, one FG was added within the ratio range of the first EVT mode, and two more FG were added within the ratio range of the second EVT mode. So, for the two-mode hybrid, the native FG between the two EVT modes is Fixed Gear 2 (FG2). The top FG ratio, Fixed Gear 4 (FG4), was added by putting a stationary clutch on one of the motors that regulates the speed ratio through the transmission, MC1. Fixed Gear 1 (FG1) and Fixed Gear 3 (FG3) were both added with a rotating clutch. The FG1 comes from locking up the input-split mode, so the speed, torque, and power from the engine go through the torque multiplication of the second planetary gear set. The FG3 comes from locking up the compound-split mode, and so the speed, torque, and power from the engine are coupled directly to the output. This study also investigates the additional two-mode EVT with fixed gears, which is called AHS2 for Rear-Wheel Drive (RWD) [5, 7]. A two-mode EVT with both an input-split mode and a compound-split mode fundamentally lowered the requirement for motor power, thus allowing the EVT to be selected as a sound basis for large cars and trucks.

\subsubsection{Equations}

To develop the plant model and the controller of the multi-mode hybrid system, we need to use equations that describe the operations of the system. To provide ease of use, the equations are simplified versions of the more complex ones. In the case of an EVT mode, only two differential equations are required to represent the powertrain system, since there are only two independent state variables - engine speed $\left(\omega_{\mathrm{e}}\right)$ and vehicle velocity $(V)$. With mathematical manipulation, the dynamic equations can be obtained as follows by using four factors, $p_{j}, q_{j}, r_{j}$ and $s_{j}$, that are specific to mode $j$ :

where

$$
\alpha \cdot \dot{X}=\beta \cdot u
$$

$$
\begin{aligned}
& X=\left[\begin{array}{ll}
\omega_{e} & V
\end{array}\right]^{T}, u=\left[\begin{array}{llll}
T_{e} & T_{M C 2} & T_{M C 1} & F_{L}
\end{array}\right]^{T}, \\
& \alpha=\left[\begin{array}{cc}
J_{e}+p_{j}^{2} J_{M C 2}+r_{j}^{2} J_{M C 1} & p_{j} q_{j} J_{M C 2}+r_{j} s_{j} J_{M C 1} \\
p_{j} q_{j} J_{M C 2}+r_{j} s_{j} J_{M C 1} & M+q_{j}^{2} J_{M C 2}+s_{j}^{2} J_{M C 1}+\frac{J_{W}}{R_{t}^{2}}
\end{array}\right], \\
& \beta=\left[\begin{array}{cccc}
1 & p_{j} & r_{j} & 0 \\
0 & q_{j} & s_{j} & -1
\end{array}\right]
\end{aligned}
$$

where $J_{e}$ is the inertia of the ICE, $J_{M C 2}$ and $J_{M C 1}$ are the inertia of the electric machine, $J_{w}$ is the wheel inertia, $R_{t}$ is the tire radius, $M$ is the vehicle mass, and $F_{L}$ is the road load. $T$ and $\omega$ denote the torque and speed of each component. The parameters are defined in Appendix Table A-1, as well as in Appendix Table A-2. From Equation (1), the dynamics of the EVT hybrid powertrain can be represented in a statespace equation as follows:

$$
\left\{\begin{array}{l}
\dot{X}=A \cdot X+B \cdot u \\
Y=C \cdot X+D \cdot u
\end{array}\right.
$$


where

$$
\begin{gathered}
Y=\left[\begin{array}{llll}
\omega_{e} & \omega_{M C 2} & \omega_{M C 1} & V
\end{array}\right]^{T}, A=0, B=\alpha^{-1} \beta, \\
C=\left[\begin{array}{llll}
1 & p_{j} & r_{j} & 0 \\
0 & q_{j} & s_{j} & 1
\end{array}\right]^{T}, D=0
\end{gathered}
$$

In the case of a FG mode, the speed and torque relationships are similar to those of a conventional multispeed transmission. They are given as follows:

$$
\begin{gathered}
T_{o}=k_{e}^{i} \cdot T_{e}+k_{M C 2}^{i} \cdot T_{M C 2}+k_{M C 1}^{i} \cdot T_{M C 1} \\
\left\{\begin{array}{c}
\omega_{e}=k_{e}^{i} \cdot \omega_{o} \\
\omega_{M C 2}=k_{M C 2}^{i} \cdot \omega_{o} \\
\omega_{M C 1}=k_{M C 1}^{i} \cdot \omega_{o}
\end{array}\right.
\end{gathered}
$$

where $T_{o} / \omega_{o}$ is the output torque/speed of the transmission, and $k^{i}$ is the multiplication ratio for each component, as given in Appendix Table A-3.

\subsection{PHEV Powertrain System}

\subsubsection{GM Volt Powertrain System}

The series engine configuration is often considered to be closer to a pure electric vehicle when compared to a parallel configuration. In this case, the vehicle is propelled solely from the electrical energy. Engine speed is completely decoupled from the wheel axles, and its operation is independent of vehicle operations. As a result, the engine can be operated consistently in a very high efficiency area.

GM Volt system employs a planetary gear as its power-split device. The GM Volt is an output split-type vehicle, with engine power split at the output. Unlike the plug-in series, two clutches and one brake are applied in the powertrain system, which allows multiple driving modes for the vehicle. The structure of GM Volt is shown in Figure 5. The engine and MC2 are connected through clutch CL1, and MC2 is connected to the ring gear through clutch CL2. The ring gear is also connected to brake, $\mathrm{BL} 1 . \mathrm{MC} 1$ is connected to the sun gear, and the carrier is connected to the vehicle's final reduction gear.

By setting the engagement and disengagement of the clutches and brake as shown in Table 1, the GM Volt is driven in four modes: the EV1, EV2, series and power-split modes. The EV1 and EV2 modes are called "Charge-Depleting (CD) modes", while the series and power-split modes are called "Charge-Sustaining (CS) modes" [9]. In the CD mode, the battery is the only power source, and the vehicle operation depends on

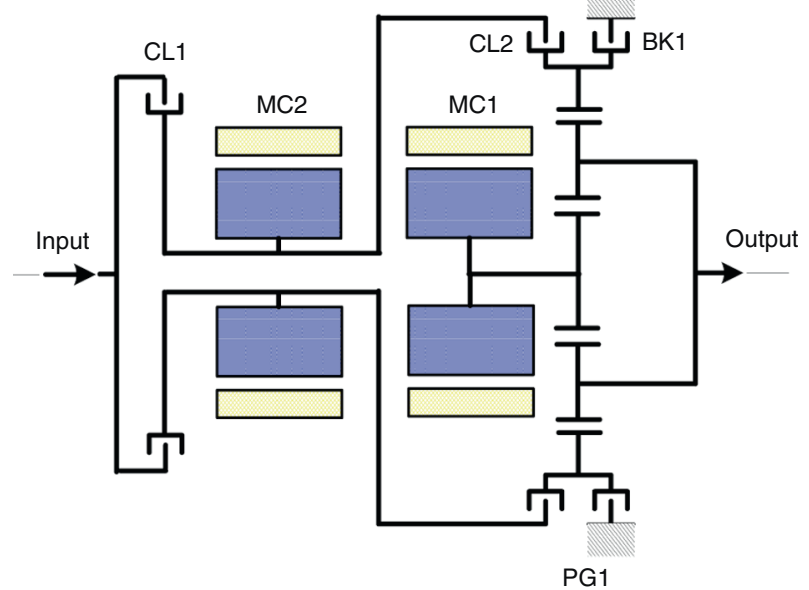

Figure 5

Schematic of the GM Voltec.

TABLE 1

System operation schedule of GM Volt [10]

\begin{tabular}{l|c|c|c}
\hline & \multicolumn{3}{|c|}{ System operation schedule } \\
\hline Mode & BK1 & CL1 & CL2 \\
\hline EV1 & On & Off & Off \\
\hline EV2 & Off & Off & On \\
\hline Series & On & On & Off \\
\hline Power split & Off & On & On \\
\hline
\end{tabular}

the energy from the battery. In the CS mode, the engine serves as the main power source while sustaining the battery SOC.

In Figure 6, in low SR range, the system efficiency is low because the electrical machines have relatively low efficiency. This low system efficiency can be avoided by propelling the vehicle by using the series mode instead of the split mode.

\subsubsection{Equations}

The speed relationship of the powertrain components and the vehicle dynamic models was obtained by using the following equations:

$$
\omega_{\text {out }}=a \cdot \omega_{M C 1}+b \cdot \omega_{M C 2}=V \cdot \frac{N_{d}}{R_{t}}
$$

where $N_{d}$ is the final reduction gear ratio. 

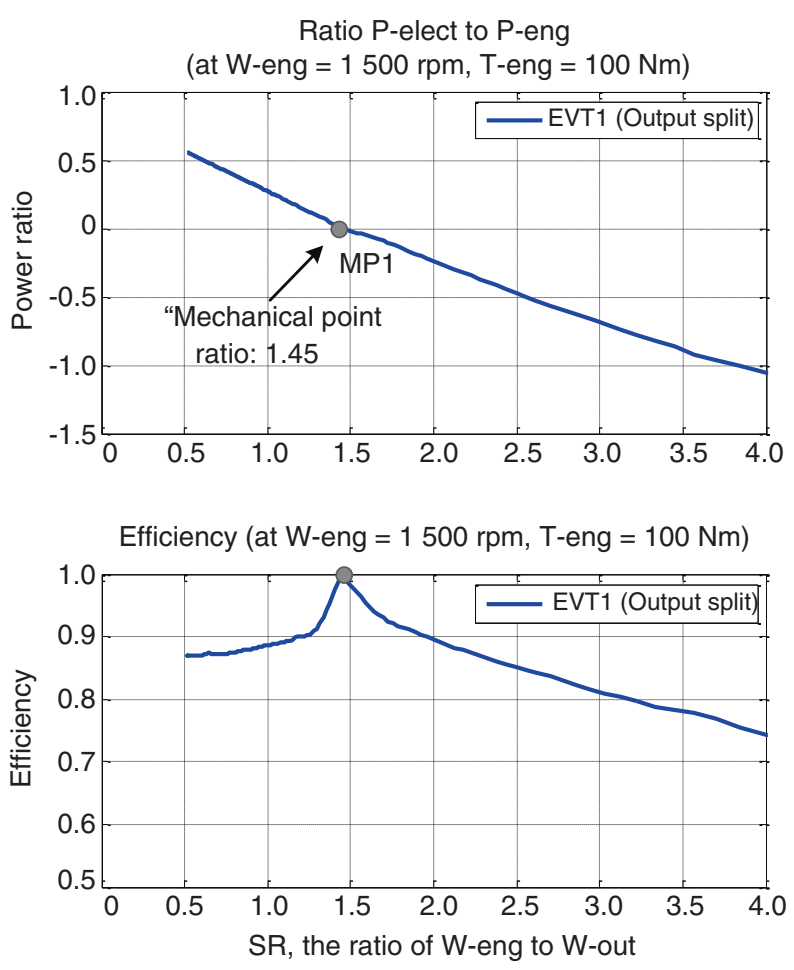

Figure 6

Power characteristics of the GM Voltec.

The dynamic models of the transmission in the GM Volt for the EV1 and EV2 modes were derived as follows:

$T_{\text {out }}=\frac{1}{a} \cdot T_{M C 1}-\frac{1}{a^{2}} \cdot J_{M C 1} \cdot \dot{\omega}_{\text {out }}$
$T_{\text {out }}=\frac{1}{a} \cdot T_{M C 1}-\frac{1}{a^{2}} \cdot J_{M C 1} \cdot \dot{\omega}_{\text {out }}+\frac{b}{a^{2}} \cdot J_{M C 1} \cdot \dot{\omega}_{M C 2}$

In the series mode, the dynamic equation of $\mathrm{MC} 1$ was the same as that shown in Equation (6), and the dynamic equation of the engine and MC2 was obtained as follows:

$$
\left(J_{e}+J_{M C 2}\right) \cdot \dot{\omega}_{e}=T_{e}+T_{M C 2}
$$

In the power-split mode, the dynamic equation of $\mathrm{MC} 1$ was the same as that shown in Equation (7), and the dynamic equation was derived as:

$$
\begin{aligned}
& \left(J_{e}+J_{M C 2}+\frac{b^{2}}{a^{2}} \cdot J_{M C 1}\right) \cdot \dot{\omega}_{e}-\frac{b}{a^{2}} \cdot J_{M C 1} \cdot \dot{\omega}_{\text {out }} \\
& \quad=T_{e}+T_{M C 2}-\frac{b}{a} \cdot T_{M C 1}
\end{aligned}
$$

\section{COMPONENT SIZING}

\subsection{Modeling the Vehicle in Autonomie}

Autonomie is a forward-looking modeling tool that can simulate a broad range of powertrain configurations [11]. The driver model computes the torque demand needed to meet the vehicle speed trace. The torque demand is interpreted by a high-level controller that computes the component's torque demands while ensuring that the system operates within its constraints. Detailed transmission models were developed by using SimDriveline, including specific losses for gear spin and hydraulic oil [12], as shown in Figure 7. Such a level of detail is necessary to properly assess the trade-off between complexity and efficiency.

\subsection{Mode Selection During Acceleration}

The powertrain must be operated in such a way that the output shaft can transmit the maximum torque from the powertrain to the final drive. This can be regarded as an optimization problem, and it is solved for the corresponding vehicle speed. An off-line computation was used to generate the maximum powertrain torque that could be used in Simulink, indexed by gearbox output speed and battery power. To compute that look-up table, a brute-force algorithm is used, possibly several hundreds of times, along an output speed grid ranging from 0 to its maximum.

The maximum powertrain torque curves are obtained along the scheme and displayed in Figure 8. In acceleration simulations, the mode that allows the maximum output torque is selected. Figure 8 shows the tractive capability of the system with FG, on the basis of the optimum selection of engine speed, to provide the highest level of tractive output. From this graph, in Figure 8a, it can be seen that FG1 increases the vehicle tractive capability significantly in the range of $10-45 \mathrm{mph}$. The use of FG1 over a large range of vehicle speeds eliminates the need to use the motors for processing engine power, thereby freeing up capacity to boost acceleration.

\subsection{Sizing Process}

To quickly size the component models of the powertrain, an automated sizing process was used [13]. The sizing process defines the peak mechanical power of the electric machine as being equal to the peak power needed to follow the acceleration constraints. The peak discharge power of the battery is then defined as the electrical power that the electric machine requires to produce its peak mechanical power. The sizing process then 


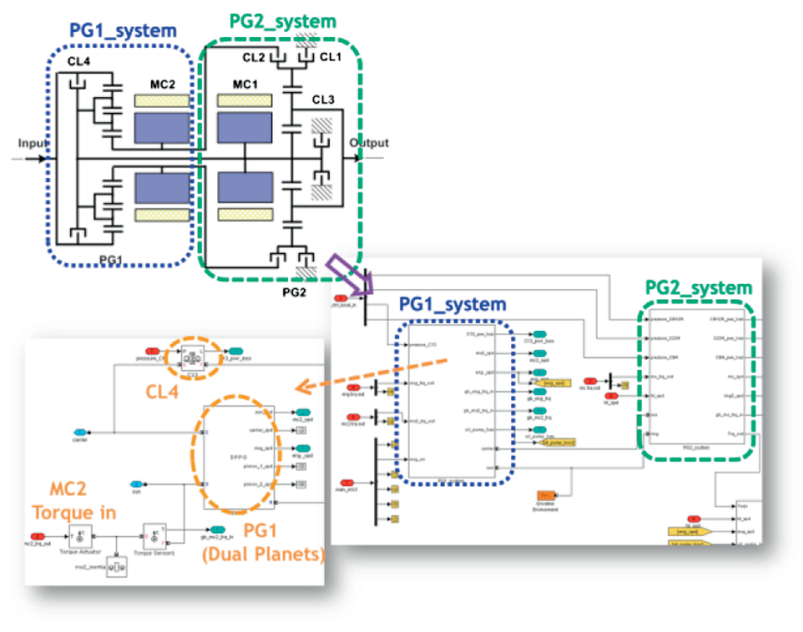

Figure 7

Transmission model for the AHS2 FWD.

calculates the peak power of the engine by using the power of the drivetrain required to achieve the gradeability requirement of the vehicle.

As detailed previously, the component's characteristics determine the constraints. The main vehicle characteristics used in this study are summarized in Table 2. In particular, the ratios of planetary gear sets are derived from patents and references. The 0-60-mph performance requirement for the vehicle is satisfied implicitly by the constraints on the peak motor power and the peak engine power. The power required by the motor for the vehicle to follow the UDDS cycle added to the power required by the engine for the vehicle to drive up a $13 \%$ grade at $65 \mathrm{mph}$ exceeds the power that the vehicle needs to go from 0 to $60 \mathrm{mph}$ in $7.8 \mathrm{~s}$.

To meet the All-Electric Range (AER) requirements for a PHEV, the battery power is sized to follow the Urban Driving Dynamometer Schedule (UDDS) driving cycle while in all-electric mode. We also ensure that the vehicle can capture the entire energy from regenerative braking during decelerations on the UDDS. Finally, battery energy is sized to achieve the required AER of the vehicle. The AER is defined as the distance the vehicle can travel on the UDDS until the first engine start. Note that a specific control algorithm is used to simulate the AER. This algorithm forces the engine to remain off throughout the cycle, regardless of the torque request from the driver.

The selected vehicle class for PHEV represents a midsize sedan. The main characteristics are defined in Table 3 .
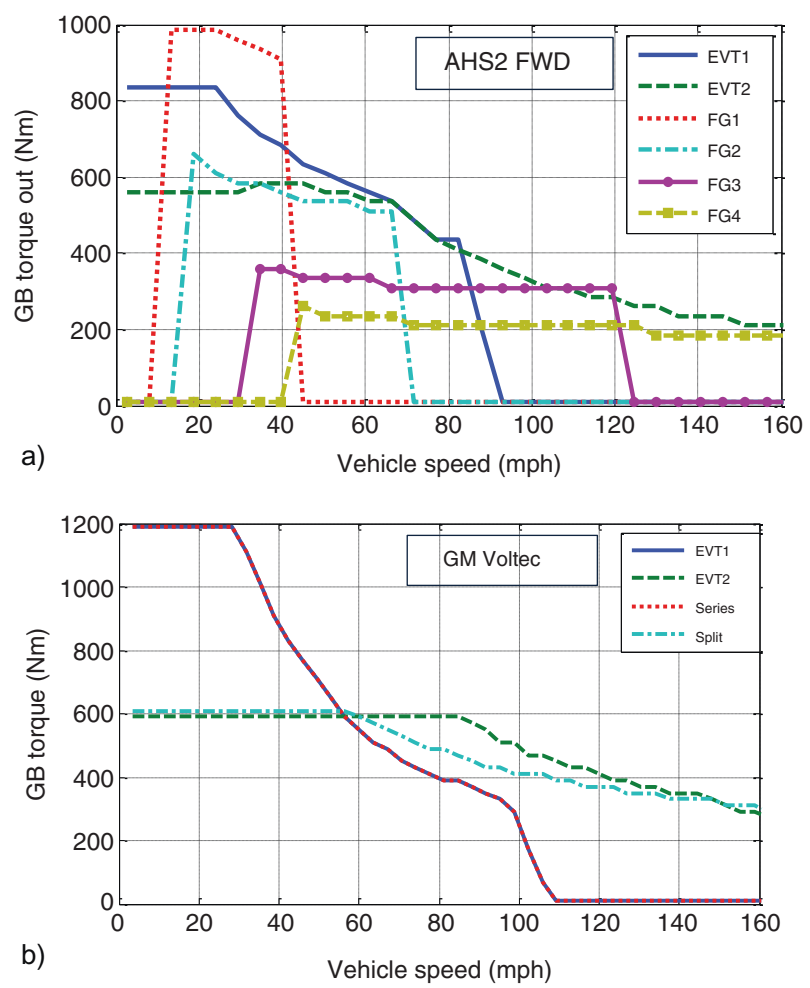

Figure 8

Max torque during acceleration - a) two-mode EVT with FG (AHS2 FWD), b) GM Voltec.

TABLE 2

Specifications of the small-size SUV for HEV

\begin{tabular}{c|c|c|c}
\hline $\begin{array}{c}\text { Body and chassis } \\
\text { mass }\end{array}$ & $1180 \mathrm{~kg}$ & Frontal area & $2.64 \mathrm{~m}^{2}$ \\
\hline Drag coefficient & 0.37 & Wheel radius & $0.3423 \mathrm{~m}$ \\
\hline Final drive ratio & \multicolumn{2}{|c}{$\begin{array}{c}\text { Single mode: } 4.11 \\
\text { Multi mode: } 3.02\end{array}$} \\
\hline PG ratio $(\mathrm{Zr} / \mathrm{Zs})$ & \multicolumn{3}{|c}{$\begin{array}{c}\text { Single mode: } 2.6 \\
\text { Single mode with RG: } 2.4,2.0 \\
\text { AHS2 FWD: } 2.36,2.24\end{array}$} \\
& $\begin{array}{r}\text { AHS2 RWD: } 1.93,1.97,2.6 \\
\hline\end{array}$
\end{tabular}

The components of the different vehicles for PHEV were sized to meet the following vehicle performance standards:

- 0-60 mph < $9 \mathrm{~s}$;

- Gradeability of $6 \%$ at $65 \mathrm{mph}$;

- Maximum speed > $100 \mathrm{mph}$.

\subsection{Sizing Results}

\subsubsection{Single-Mode EVT vs Multi-Mode EVT}

The sizing results for HEV are summarized in Figure 9 and Appendix Table A-4. For comparison, two single-mode 
TABLE 3

Specifications of the mid-size sedan for PHEV

\begin{tabular}{c|c|c|c}
\hline Body and chassis mass & $950.2 \mathrm{~kg}$ & Frontal area & $2.22 \mathrm{~m}^{2}$ \\
\hline Drag coefficient & 0.275 & Wheel radius & $0.317 \mathrm{~m}$ \\
\hline Final drive ratio & \multicolumn{3}{|c}{ Series PHEV: 4.44} \\
GM Voltec: 3.02 \\
\hline PG ratio $(\mathrm{Zr} / \mathrm{Zs})$ & $\begin{array}{c}\text { Series PHEV (Manual 2 spd): } 1.86,1 \\
\text { GM Voltec: } 2.24\end{array}$ \\
\hline
\end{tabular}

EVT hybrid systems and two multi-mode EVT hybrid systems are investigated, and the results are presented. As noted in the introduction, the multi-mode system results in significant improvements in dynamic performance at reduced capacities of the electro-mechanical power. As can be seen in Figure 9, the capacities saved by the multi-mode system range from $31.7 \%$ to $64.3 \%$, relative to the single-mode system. The main contributor is the addition of the EVT mode, which causes the difference between the single-mode and multi-mode systems.

\subsubsection{Series PHEV vs GM Voltec}

The main characteristics of the sized vehicles are described in Table 4. Note that engine power is similar for the series and GM Voltec. The sizing result shows that the GM Voltec powertrain requires lower component power to meet the VTS than does a series system because of the use of an additional driving mode. Because the electric machine is the only component used in the series to propel the vehicle, its power is also higher than that in the GM Voltec configuration.

\section{CONTROL STRATEGY}

\subsection{Mode Shift Strategy}

To evaluate the benefits of several multi-mode powertrain configurations from the standpoint of fuel consumption, a control strategy is required first. One of the major challenges of the multi-mode control strategy is to properly select the operating mode. To develop a mode shift strategy, a brute-force algorithm is used. The algorithm generates an optimal input speed and torque for each EVT mode, indexed by gearbox output speed, battery power, and gearbox output torque. By knowing these parameters, we can compute the fuel power and compare it with that in the other EVT modes

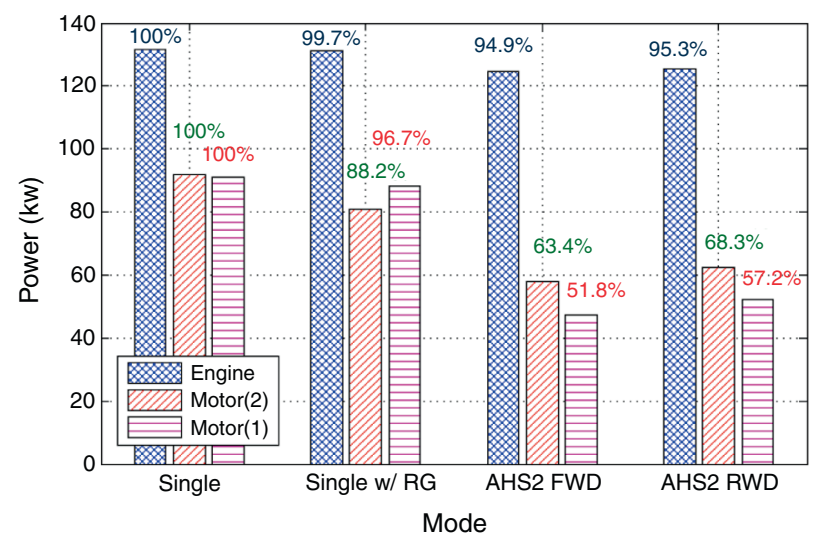

Figure 9

Component sizing results.

TABLE 4

Component size - 400-mi AER case

\begin{tabular}{l|c|c}
\hline Parameter & Plug-in series & GM Voltec \\
\hline Engine power $(\mathrm{kW})$ & 77.1 & 69.9 \\
\hline MC1 power $(\mathrm{kW})$ & 129.4 & 125.8 \\
\hline MC2/generator $(\mathrm{kW})$ & 74.8 & 69.9 \\
\hline Battery capacity $(\mathrm{kWh})$ & 17.6 & 16.8 \\
\hline Vehicle mass $(\mathrm{kg})$ & 1900 & 1865 \\
\hline
\end{tabular}

$[14,15]$. Meanwhile, a candidate input set for FGs is obtained in the conventional way. Figure 10a depicts the optimal mode selections for various output load conditions. If we convert these results into a new map by using vehicle speed and engine speed indexes, the mode selection rule is defined on the basis of the speed ratio. The reason for this is because the selected optimal mode could be divided according to the speed ratio, which is defined as the ratio of the target engine speed to the output speed. When in propelling mode, the target engine speed has been previously computed by the simplified optimal system operating line for driver power demand. In Figure 10b, the FG2 mode appears in the transition area between the EVT1 and EVT2 modes. The FG2 mode is inherent in the modes needed for the synchronous shift between the two EVT modes. The FG4 mode supplements the EVT2 mode. The logic was validated for both single-mode and two-mode hybrid systems by using vehicle test data [16]. Similar algorithms were implemented for the GM Voltec configurations. 

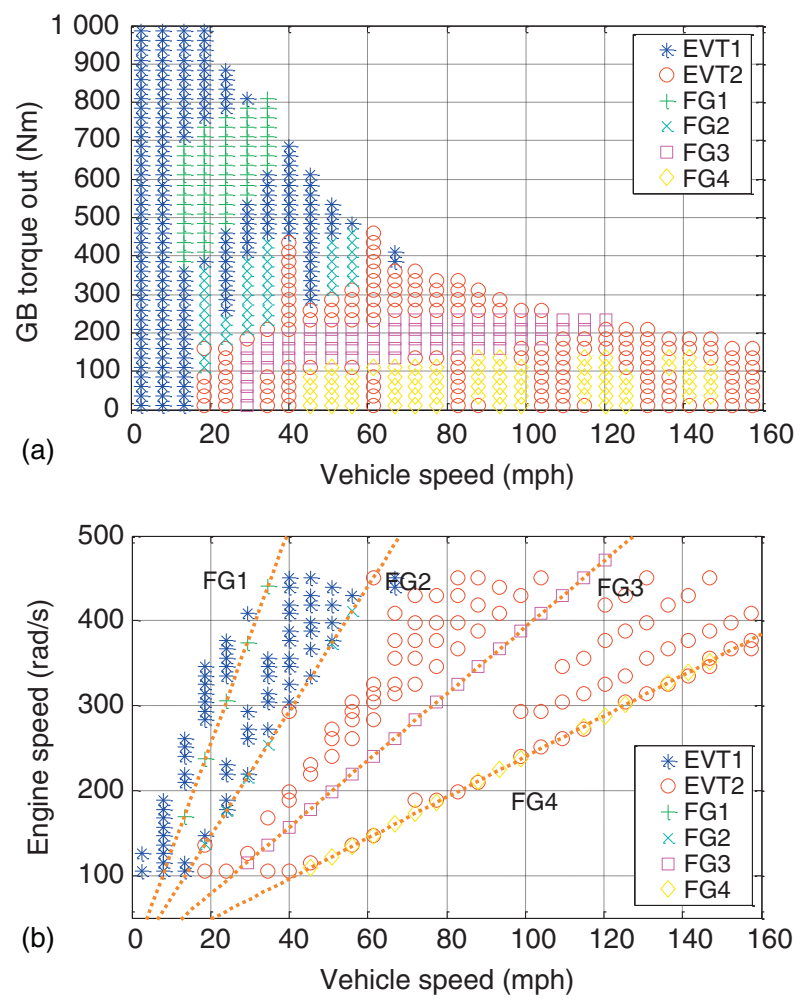

Figure 10

Mode shift maps for AHS2 FWD.

\subsection{Energy Management Strategy for PHEV}

According to sizing results, the average all-electric range of the PHEV is almost $40 \mathrm{mi}$. To achieve this electric driving range, an energy management strategy must be developed.

The developed energy management strategy is shown in Figure 11. When the battery is being charged, the upper SOC threshold is set at 0.9 because of the efficiency problem. When the initial battery SOC is 0.9 , the vehicle is driven in the $\mathrm{CD}$ mode at engine start. In the CD mode, the GM Voltec is driven in the EV1 or EV2 mode, depending on the driving conditions. The battery is the only power source in the $\mathrm{CD}$ mode. When the battery SOC decreases and reaches 0.25 , the vehicle operation mode switches to the CS mode. The engine now works as the power source. The engine supplies the demanded vehicle power and maintains the battery SOC at around 0.25 . When the battery SOC reaches 0.3 , the driving mode of the vehicle is reverted back to the $\mathrm{CD}$ mode. By using this algorithm, as much electric energy as can be consumed is consumed to obtain better fuel efficiency.

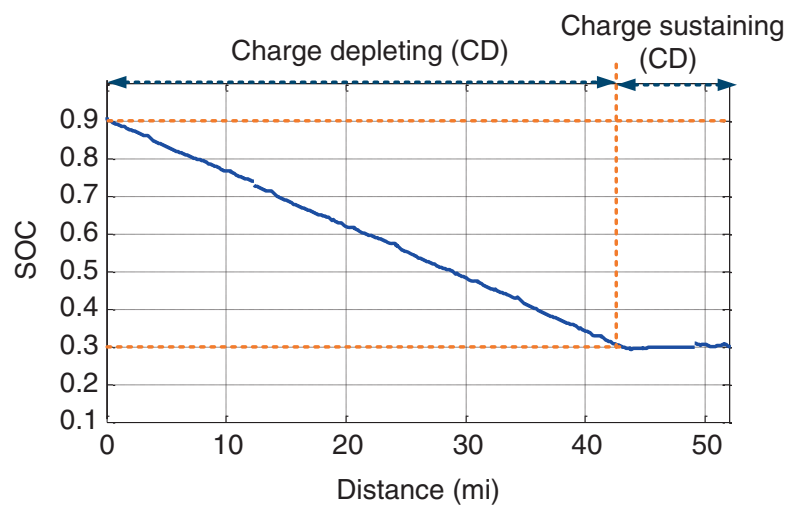

Figure 11

Control strategy SOC behavior.

For the GM Voltec configuration, driving mode is an integral part of the energy management strategy. For the CD mode, the transmission efficiency map of EV1 and EV2 mode can be calculated by considering the motor efficiency and transmission loss. On the basis of the efficiency map, the shift map can be constructed for the CD mode. As a result, the EV1 or EV2 mode can be selected by the battery SOC, vehicle velocity, and drive demand torque.

\section{SIMULATION RESULTS}

\subsection{Comparative Analysis of HEVs}

With the transmission models and controller described in the previous section, the vehicle was simulated on standard drive cycles: the Urban Dynamometer Driving Schedule (UDDS); the HighWay Fuel Economy Test (HWFET) cycle; the New European Driving Cycle (NEDC); a more aggressive urban cycle with some short highway cycles (LA92); and a highly aggressive cycle, predominantly at high speed (US06). The fuel economy results are reported in Figure 12. For urban driving, the single-mode hybrid system has relatively high fuel economy compared with the multi-mode hybrid system. On the other hand, the trend shown by the different cycles indicates that the higher the speed of the driving pattern, the greater the advantage of the multi-mode hybrid system. As a consequence, the AHS2 FWD provides a greater advantage in terms of fuel consumption for the vehicle application considered on the small-size SUV specification.

Figure 13 reports the operating points of the powertrain for urban and highway driving. It is remarkable 


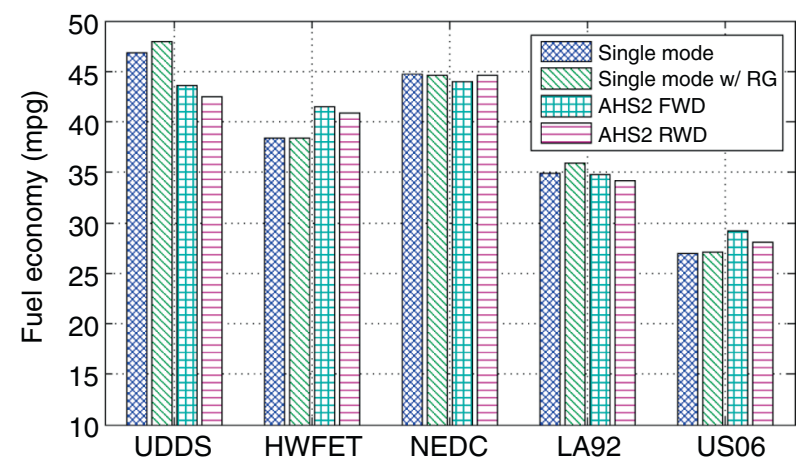

Figure 12

Fuel economy summary.

how the vehicles operate in the regions of higher efficiency to reduce fuel consumption. As shown in Figure 13, the single-mode hybrid system has relatively lower system efficiency in the primary operating region, for highway driving. This occurs because the electromechanical power increases sharply as the transmission reaches higher overdrive. The operating points of the multi-mode hybrid system are between the mechanical points to achieve the high EVT efficiency. For the multi-mode hybrid system, highway cycles favor the use of fixed gears.

Table 5 shows the efficiencies of all three power sources and powertrains. The transmission efficiency refers only to the all-mechanical path. The single-mode hybrid system has the highest transmission efficiency, since there is no need for more planetary gears or clutches. For the multi-mode system with the FG, it is interesting to note that the efficiencies of the ICE are not particularly high. This effect is due to the fixed gear, which improves the highway fuel economy by avoiding the lower system efficiency region to maintain holding torque at the second mechanical point.

\subsection{Comparative Analysis of PHEVs}

The series is mainly driven in the EV and HEV modes but the GM Voltec has four driving modes. In the CD mode, GM Voltec has the EV1 and EV2 modes to drive the vehicle at low and high speed. In the GM Voltec, only $\mathrm{MC} 1$ is used to propel the vehicle, and MC2 does not work in the EV1 mode. Furthermore, MC2 and $\mathrm{MC} 1$ propel the vehicle together in the EV2 mode. In Figure 14a, it can be seen that the MC1 torque shows a similar performance, even if the vehicle is driven in a
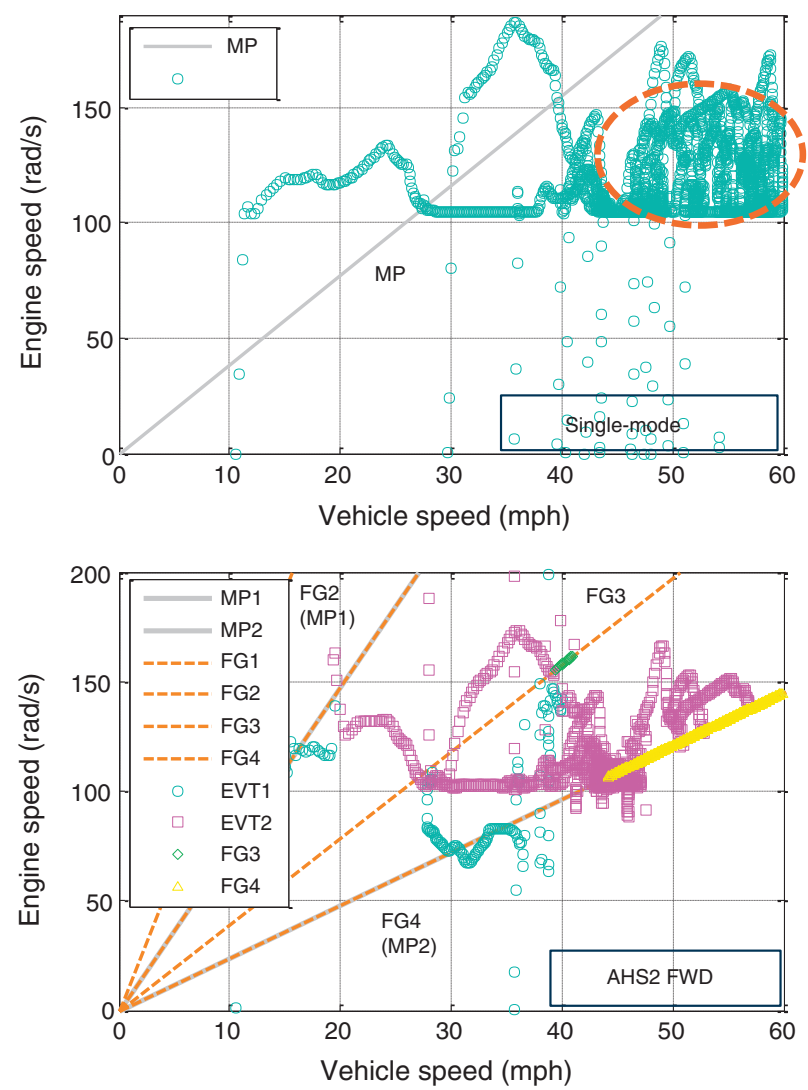

Figure 13

Operating points for HWFET.

different driving mode. This shows that the MC1 torque of the GM Voltec is determined only by the demanded wheel torque and is operated regardless of the driving mode, which implies that MC1 should have a power capacity that is large enough to drive the vehicle while satisfying the demanded power. This explains why the capacity of $\mathrm{MCl}$ in the GM Voltec is $125 \mathrm{~kW}$, which is similar to the capacity of $\mathrm{MC} 1$ in the plug-in series. In the plug-in series, as shown in Figure 14a, in the EV mode, only $\mathrm{MCl}$ is used to propel the vehicle, and MC2 does not work.

In the CS mode, GM Voltec has the series and powersplit modes at low and high vehicle speeds. When the GM Volt is driven in the series mode, MC2 works as a generator and supplies the electric power required for MC2 to propel the vehicle. In the power-split mode, even if MC2 can be used for optimal engine operation for both PHEV, the role of MC2 in the GM Voltec is different from that in the plug-in series. In the GM Voltec, $\mathrm{MC} 2$ assists the engine to produce the demanded torque 
TABLE 5

Component average efficiencies $(\%)$

\begin{tabular}{c|c|c|c|c}
\hline UDDS & S1 & S2 & M1 & M2 \\
\hline Engine & 33.3 & 33.4 & 30.9 & 31.1 \\
\hline MC1 & 87.0 & 87.5 & 86.5 & 86.7 \\
\hline MC2 & 86.2 & 86.1 & 86.0 & 86.0 \\
\hline TM & 96.1 & 96.4 & 90.5 & 89.5 \\
\hline PT & 33.5 & 33.6 & 31.6 & 30.9 \\
\hline HWFET & S1 & S2 & M1 & M2 \\
\hline Engine & 33.8 & 33.7 & 31.6 & 30.6 \\
\hline MC1 & 91.4 & 89.9 & 86.6 & 87.2 \\
\hline MC2 & 86.5 & 86.5 & 86.6 & 86.6 \\
\hline TM & 94.7 & 93.4 & 89.0 & 88.9 \\
\hline PT & 25.9 & 26.0 & 26.7 & 26.2 \\
\hline
\end{tabular}

(S1: single mode; S2: single mode with RG; M1: AHS2 FWD; M2: AHS2 RWD; TM: transmission; PT: powertrain.)

at the ring rear and propels the vehicle together with $\mathrm{MC} 1$. In the plug-in series, MC2 works as a generator to generate electric power, while $\mathrm{MC} 1$ is only used to propel the vehicle.

The $\mathrm{J} 1711$ procedure is used to calculate the fuel economy of PHEV. Table 6 shows the electrical consumption and fuel economy results for each powertrain configuration. The GM Voltec provides the more efficient electrical consumption in CD mode. The higher efficiency of the power transfer from engine to wheels benefits the plug-in series because of the use of two electric machines. The GM Voltec also has the better fuel economy in CD mode. The series configuration suffers from dual power conversion - from mechanical (engine) to electrical (generator) and back to mechanical (electric machine). The GM Voltec configuration performs better in highway driving than in urban driving because of the power-split operation. The power split allows the engine to be operated close to its most efficient point without the engine sending all of its power through both electric machines. High engine efficiency and the ability to send mechanical power directly to the wheel allow this configuration to provide better CS fuel economy.

\section{CONCLUSION}

This paper examines the several powertrain configurations, including single-mode EVT, multi-mode EVT,
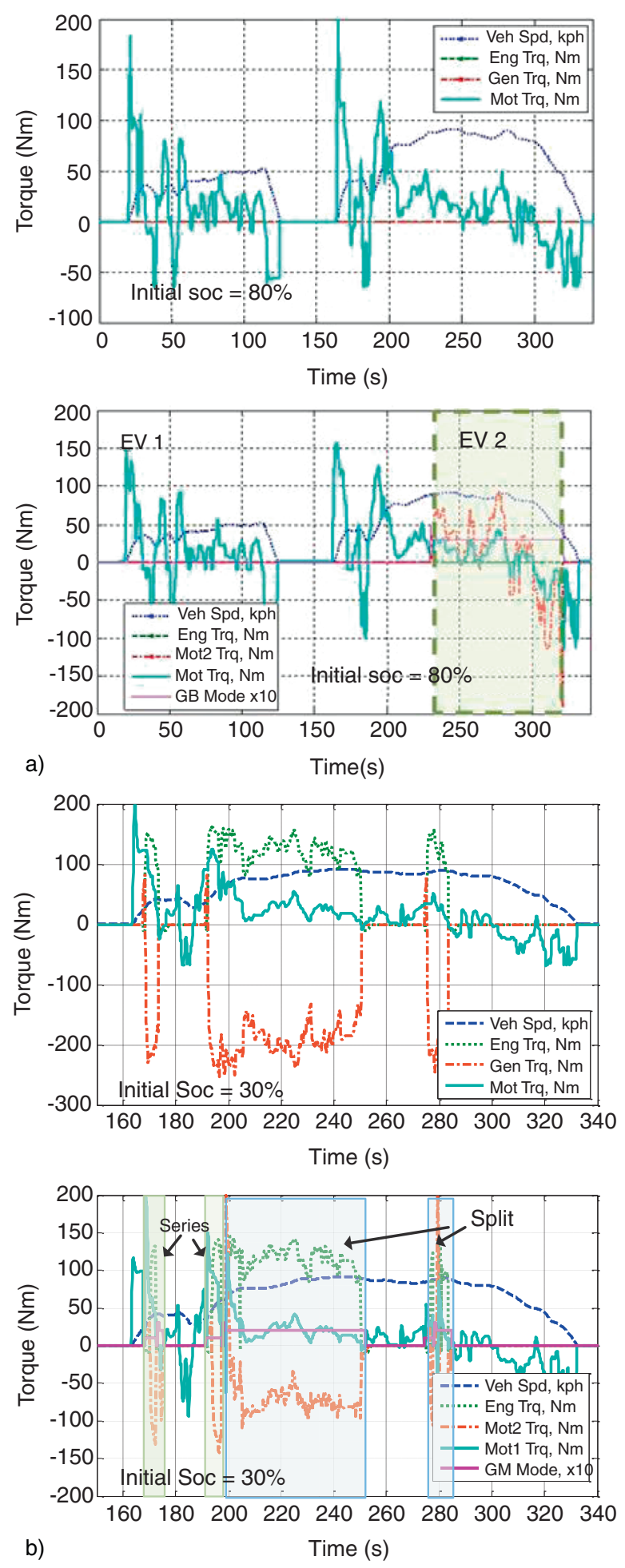

Figure 14

Comparison of component torque - a) Initial SOC $=80 \%$, (top $=$ series, bottom $=$ GM Volt); b) Initial SOC $=$ $30 \%$, (top $=$ series, bottom $=$ GM Volt). 
TABLE 6

PHEV fuel economy results

\begin{tabular}{c|c|c|c|c}
\hline \multicolumn{2}{c|}{$\begin{array}{c}\text { Electrical consumption \& } \\
\text { fuel economy }\end{array}$} & $\begin{array}{c}\text { Plug-in } \\
\text { series }\end{array}$ & $\begin{array}{c}\text { GM } \\
\text { Voltec }\end{array}$ \\
\hline \multirow{2}{*}{ UDDS } & $\mathrm{CD}$ & $\mathrm{Wh} / \mathrm{mi}$ & 265.0 & 251.7 \\
\cline { 2 - 5 } & $\mathrm{CS}$ & $\mathrm{MPG}$ & 44.5 & 46.8 \\
\cline { 2 - 5 } & \multirow{2}{*}{$\mathrm{CD}+\mathrm{CS}$} & $\mathrm{Wh} / \mathrm{mi}$ & 195.0 & 185.9 \\
\cline { 3 - 5 } & & $\mathrm{MPG}$ & 111.3 & 117.0 \\
\hline \multirow{2}{*}{ HWFET } & $\mathrm{CD}$ & $\mathrm{Wh} / \mathrm{mi}$ & 250.7 & 240.3 \\
\cline { 2 - 5 } & $\mathrm{CS}$ & $\mathrm{MPG}$ & 44.5 & 49.4 \\
\cline { 2 - 5 } & $\mathrm{CD}+\mathrm{CS}$ & $\mathrm{Wh} / \mathrm{mi}$ & 197.2 & 193.1 \\
\cline { 3 - 5 } & & $\mathrm{MPG}$ & 120.1 & 133.6 \\
\hline
\end{tabular}

series and GM Voltec and vehicle-level controls developed in autonomie. Detailed transmission models were implemented to allow a fair assessment of the benefits associated with these different powertrain architectures by comparing component sizes, system efficiency, and fuel consumption over several drive cycles.

First, single-mode EVT and multi-mode EVT were sized to represent a small-size SUV HEV application, following the same vehicle technical specifications, such as acceleration and gradeability. The results predicted that the multi-mode system would have better acceleration than a single-mode system, since the additional EVT modes significantly lower the requirement for the electric machine power. In addition, simulations were performed on a small-size SUV to characterize the impact on component operating conditions and fuel consumption for several driving cycles. It was determined that the multi-mode system has an advantage in terms of fuel economy during the high-speed cycle because of relatively higher system efficiency.

A comparative study between the PHEV GM Voltec and series powertrains was also performed. The sizing results show that the GM Voltec powertrain requires lower component power to meet the VTS than a series system because of the many component efficiencies between the engine and the wheel. In addition, simulations were performed on a midsize vehicle to characterize the impact on component operating conditions and fuel consumption on urban and highway driving. The series mode in the GM Voltec implies that a relatively larger MC2 is required for the vehicle's power requirement. In the power-split mode, MC2 is used to assist the engine in the GM Voltec, while in the plug-in series, the $\mathrm{MC} 2$ works as a generator. It was determined that the GM Voltec powertrain achieved lower fuel consumption during all driving condition modes, compared to a pure series configuration.

\section{ACKNOWLEDGMENTS}

This work was supported by DOE's Vehicle Technology Office under the direction of David Anderson and Lee Slezak. The submitted manuscript has been created by UChicago Argonne, LLC, Operator of Argonne National Laboratory ("Argonne"). Argonne, a U.S. Department of Energy Office of Science laboratory, is operated under Contract No. DE-AC02-06CH11357. The U.S. Government retains for itself, and others acting on its behalf, a paid-up nonexclusive, irrevocable worldwide license in said article to reproduce, prepare derivative works, distribute copies to the public, and perform publicly and display publicly, by or on behalf of the Government.

\section{REFERENCES}

1 Schulz M. (2004) Circulating Mechanical Power in a Powersplit Hybrid Electric Vehicle Transmission, Proc. IMechE Part D: J. Automobile Engineering 218, 1419-1425.

2 Duoba M., Lohse-Busch H., Carlson R., Bohn T., Gurski S. (2007) Analysis of Power-split HEV Control Strategies Using Data from Several Vehicles, SAE Paper 2007-010291.

3 Holmes A., Schmit M. (2002) Hybrid Electric Powertrain Including a Two-mode Electrically Transmission, US Patent, US006478705.

4 Holmes A., Schmit M., Klemen D. (2007) Electrically Variable Transmission with Selective Fixed Ratio Operation, US Patent, US007220203.

5 Schmit M., Klemen D. (2005) Two-mode Compound-split, Hybrid Electro-mechanical Transmission having Four Fixed Ratios, US Patent, US006953409.

6 Holmes A., Schmit M., Conlon B. (2010) Three-mode Electrically Variable Transmission, US Patent, US007645206.

7 Grewe T., Conlon B., Holmes A. (2007) Defining the General Motors 2-Mode Hybrid Transmission, SAE Paper 2007-01-0273.

8 Situ L. (2009) Electric Vehicle Development: The past present \& Future, 3rd International Conference on Power Electronics Systems and Applications, PESA 2009, K210509135, 20-22 May.

9 Miller M., Holmes A., Conlon B., Savagian P. (2011) The GM 'Voltec' 4ET50 Multi-Mode Electric Transaxle, $S A E$ Paper 2011-01-0887.

10 http://www.chevrolet.com/volt/

11 Vijayagopal R., Shidore N., Halbach S., Michaels L., Rousseau A. (2010) Automated Model based Design Process to Evaluate Advanced Component Technologies, SAE Paper 2010-0-0936. 
12 Kitabayashi H., Li C., Hiraki H. (2003) Analysis of the Various Factors Affecting Drag Torque in Multiple-Plate Wet Clutches, SAE Paper 2003-01-1973.

13 Sharer P., Rousseau R., Pagerit S., Nelson P. (2007) Midsize and SUV Vehicle Simulation Results for Plug-in Component Requirements, SAE Paper 2007-01-0295.

14 Ahn K., Cha S. (2008) Developing Mode Shift Strategies for a Two-mode Hybrid Powertrain with Fixed Gears, $S A E$ Paper 2008-01-0307.
15 Karbowski D., Kwon J., Kim N., Rousseau A. (2010) Instantaneously Optimized Controller for a Multi-mode HEV, SAE Paper 2010-01-0816.

16 Kim N., Carlson R., Jehlik F., Rousseau A. (2009) Tahoe HEV Model Development in PSAT, SAE Paper 2009-011307.

Final manuscript received in January 2013

Published online in April 2013 made or distributed for profit or commercial advantage and that copies bear this notice and the full citation on the first page. Copyrights for components of this work owned by others than IFP Energies nouvelles must be honored. Abstracting with credit is permitted. To copy otherwise, to republish, to post on servers, or to redistribute to lists, requires prior specific permission and/or a fee: Request permission from Information Mission, IFP Energies nouvelles, fax. + 331475270 96, or revueogst@ifpen.fr. 


\section{APPENDIX}

TABLE A-1

Definitions of ratio variables

\begin{tabular}{l|c|c|c|c|c}
\hline Configuration & EVT & $p_{j}$ & $q_{j}$ & $r_{j}$ & $s_{j}$ \\
\hline Single mode & - & $\mathrm{a}+1$ & $-a z$ & 0 & $\mathrm{z}$ \\
\hline Single mode w/RG & - & $\mathrm{a}+1$ & $-a z$ & 0 & $b z$ \\
\hline AHS2 FWD & 1 & $a$ & $-b c z$ & 0 & $c z$ \\
\hline & 2 & $\frac{a}{1-b d}$ & $\frac{-b c z}{1-b d}$ & $\frac{-a d}{1-b d}$ & $\frac{c z}{1-b d}$ \\
\hline AHS2 RWD & 1 & $\frac{-a}{1-b c}$ & $\frac{b d e z}{1-b c}$ & 0 & $e z$ \\
\hline & 2 & $-a$ & $b z$ & $\frac{a c}{d}$ & $\frac{(1-b c) z}{d}$ \\
\hline
\end{tabular}

where $z=\frac{\text { Final driveratio }}{\text { Whel }}$

Wheel radius

TABLE A-2

Definitions of simplified factors

\begin{tabular}{l|c|c|c|c|c|c}
\hline Configuration & $a$ & $b$ & $c$ & $d$ & $e$ & $f$ \\
\hline Single mode & $R_{1}$ & - & - & - & - & - \\
\hline Single mode w/RG & $R_{1}$ & $R_{2}$ & - & - & - & - \\
\hline AHS2 FWD & $R_{1}$ & $R_{1}-1$ & $R_{2}+1$ & $R_{2}$ & - & - \\
\hline AHS2 RWD & $R_{1}$ & $R_{1}+1$ & $\frac{R_{2}}{1+R_{2}}$ & $\frac{1}{1+R_{2}}$ & $1+R_{3}$ & $R_{3}$ \\
\hline GM Voltec & $\frac{1}{1+R_{1}}$ & $\frac{R_{1}}{1+R_{1}}$ & - & - & - & - \\
\hline
\end{tabular}

TABLE A-3

Fixed gear ratios

\begin{tabular}{l|c|c|c|c}
\hline Configuration & FG & $k_{e}^{i}$ & $k_{M C 2}^{i}$ & $k_{M C 1}^{i}$ \\
\hline AHS2 FWD & 1 & $\mathrm{c}$ & $\mathrm{c}$ & $\mathrm{c}$ \\
\hline & 2 & $\frac{b c}{a}$ & 0 & $\mathrm{c}$ \\
\hline & 3 & 1 & 1 & 1 \\
\hline AHS2 RWD & 4 & $\frac{c}{a d}$ & $\frac{c}{d}$ & 0 \\
\hline & 1 & $\mathrm{e}$ & $\mathrm{e}$ & $\mathrm{e}$ \\
\hline & 2 & $\frac{b d+e d-1}{a c}$ & $\frac{1-e d}{e}$ & $\mathrm{e}$ \\
\hline & 3 & 1 & 1 & 0 \\
\hline
\end{tabular}


TABLE A-4

Component sizing results

\begin{tabular}{l|c|c|c|c|c}
\hline Configuration & ICE $(\mathrm{kW})$ & MC2 $(\mathrm{kW})$ & MC1 $(\mathrm{kW})$ & Battery $($ Cells $)$ & Mass $(\mathrm{kg})$ \\
\hline Single mode & 131.5 & 91.7 & 91.2 & 180 & 1953 \\
\hline Single mode w/RG & 131.1 & 80.9 & 88.2 & 173 & 1940 \\
\hline AHS2 FWD & 124.8 & 58.1 & 47.2 & 170 & 1875 \\
\hline AHS2 RWD & 125.3 & 62.6 & 52.2 & 171 & 1883 \\
\hline
\end{tabular}

